\author{
Revista Minelor - Mining Revue \\ ISSN-L 1220-2053 / ISSN 2247-8590 \\ vol. 27, issue 3 / 2021, pp. 86-92
}

\title{
DETERMINATION OF DIAGNOSTIC PARAMETERS OF POWER PLANTS BASED ON INTERNAL COMBUSTION ENGINES
}

\author{
Stefan ZAICHENKO ${ }^{1 *}$, Ümran ERÇETIN ${ }^{2}$, Roman KULISH ${ }^{3}$, Denis DEREVYANKO ${ }^{4}$, \\ Vadim SHALENKO \\ ${ }^{1}$ Igor Sikorsky Kyiv Polytechnic Institute, Kiev, Ukraine \\ ${ }^{2}$ Dumlupınar University, Kütahya, Turkey \\ ${ }^{3}$ Igor Sikorsky Kyiv Polytechnic Institute, Kiev, Ukraine \\ ${ }^{4}$ Igor Sikorsky Kyiv Polytechnic Institute, Kiev, Ukraine \\ ${ }^{5}$ Kyiv National University of Construction and Architecture, Kiev, Ukraine
}

DOI: $10.2478 / \operatorname{minrv}-2021-0028$

\begin{abstract}
The presented article shows a method for finding monitored parameters for creating a diagnostic system for autonomous power sources based on spark ignition engines and diesel engines. The classification of structures of autonomous power sources based on internal combustion engines has been carried out. The analysis of the design features of the most common back-up power sources on the market based on internal combustion engines (ICE) indicates the widespread use of generators with a synchronous alternator. The analysis of the design features of autonomous power supplies has made it possible to develop logical models for different designs. The influence of the occurrence of a faulty state of each element on other elements of the systems is analyzed, and the results of the analysis are summarized in tables. An informative Claude Chenon criterion is proposed for finding the optimal number of diagnostic parameters among an infinite number of possible combinations of physical parameters that characterize the system. When solving the problem, a hypothesis was proposed about the equiprobability of cases of exit from the working state of each of the elements of the system. The use of Claude Chenon allows you to find the parts that make up the generators, which with maximum efficiency reduce the degree of uncertainty in the system. After determining the residual entropy, the parts of the system are selected, the state of which should be monitored by the diagnostic system. For such parts of the system, diagnostic parameters are found and methods for obtaining them are indicated.
\end{abstract} Keywords: diagnostic system, power source, internal combustion engine, gasoline generator, diesel generator

\section{Introduction}

Reliable energy supply of mining enterprises is one of the fundamental aspects of stable operation of organizations in this field. Shutdown due to power outages can lead to significant financial losses as well as serious accidents. That is why it is so important when building a power supply system for a mining company to first provide reliable equipment for the main and backup power supply of the facility. These features significantly limit the use of alternative energy sources as a reliable autonomous power source [1,2]. The presence of a reliable backup power supply at a modern enterprise is the key to safe and quality work.

The only reliable and cost-effective solution for backup power supplies are power plants based on internal combustion engines (ICE). The use of this type of equipment for the generation of electricity by military and ship power plants is evidence of its highest reliability and safety among the possible options for autonomous power supply $[3,4,5]$.

The frequency of use of the backup power supply depends on the reliability of the main power supply system and can range from single starts per year to daily use. The readiness of the equipment is significantly reduced, both in the first case due to intensive wear and in the second due to intensive aging of the polymer

\footnotetext{
* Corresponding author: Zaichenko Stefan, prof. Ph.D., Igor Sikorsky Kyiv Polytechnic Institute, Kiev, Ukraine, (Peremohy Ave, 37, Kyiv, Ukraine, 03056, zstefv@gmail.com)
} 
elements of the system and deterioration of fuel and lubricants, leading to deposits in the power supply channels of the internal combustion engine. These processes that take place in autonomous power supplies based on internal combustion engines require constant monitoring to be able to use this equipment as a backup power source. The solution to this problem is to develop a system for diagnosing autonomous energy sources based on internal combustion engines.

When solving the problem of determining the technical condition of autonomous energy sources based on internal combustion engines, researchers, depending on the field of their activity, pay attention to the mechanical (internal combustion engine) or electromechanical part (alternator) of the object [6, 7, 8, 9]. Considering only a part of the object, possible conditions and diagnostic indicators are distinguished, which can determine the state of only a separate component. Thus, to determine the state of the object it is necessary to implement a set of tests for individual components, which significantly increases the time and cost of diagnosis. It is possible to minimize the costs of the diagnostic process when considering the object as a whole with the definition of its structure, possible conditions and the necessary checks.

The purpose of this study is to develop a new system of technical diagnostics based on the definition of the main diagnostic structural elements and states of autonomous energy sources based on internal combustion engines, taking into account the interaction of electromechanical and mechanical components.

To achieve this goal, the following tasks were solved in the work:

- Development of the structural scheme of energy sources on the basis of internal combustion engines taking into account features of interaction of electromechanical and mechanical components that will allow to establish mutual influences of various parts of object of research on its condition;

- Determination of possible states of autonomous energy sources on the basis of internal combustion engines;

- Establish the necessary checks to determine the status of autonomous energy sources based on internal combustion engines.

\section{Material and results of the study}

When developing a block diagram of an autonomous power source (ADEE) based on a diesel engine, consider a typical design that has found the greatest application in enterprises and private households. The prototype of most stations present on the Ukrainian market are Honda gasoline generators with a capacity of $2.5-5 \mathrm{~kW}$ and diesel generators HYUNDAI and Forte with a capacity of $2.5-5.5 \mathrm{~kW}$. The data line of gasoline generators uses a four-stroke internal combustion engine with air cooling from 163 to $408 \mathrm{~cm}^{3}$. A feature of this type of engine is the lack of a pressure lubrication system - lubrication is by spraying. The fuel system is based on the P19 series float carburetor. Most diesel fuel generators have a common rail fuel system. The gas distribution system includes lateral two-valve SOHC control with a lower camshaft and constant phases. Most generators use a synchronous electric generator with automatic voltage regulator (AVR) as an alternator, which contains the rotor and stator windings. The rotor speed of the generator is maintained by a centrifugal frequency regulator connected to the carburetor. There are different variations in the layout of individual components, for example, the design of the engine allows the conversion of the fuel system to a mixed system: fuel and gas. The engine start system can also be different: manual start, electric or combined. An electronic circuit with a flywheel magnet is used as the ignition system.

Based on the analysis of the operation of autonomous power sources on the basis of internal combustion engines, a logical model of gasoline and diesel generators was developed (Fig. 1 and Fig. 3, respectively). Of the structures of logic circuits, it should be noted the mutual influence of the engine and alternator units, which confirms the need to consider the system as a whole.

In order for the diagnostic system to work with maximum efficiency, in each case it is necessary to solve the problem of choosing the minimum sufficient number of diagnostic parameters [10]. One of the main criteria for choosing the diagnostic parameter of the system among the possible physical parameters that characterize the technical condition is informative. The diagnostic parameter selected by the informative criterion allows you to most likely determine the state of the object under study.

To select the diagnostic parameters, use the block diagram of the gasoline generator (Fig. 1). The system under consideration consists of elements. For possible states, we take the failure of each element. We plan to control the status of an autonomous source by the number of parameters equal to the number of elements. It should be noted that in the General case, each of the elements may have several diagnostic parameters. As a result of research of failures of elements of system the table of states (table 1) is created. The probability of failure of each element for preliminary consideration will be equal: 


$$
P\left(S_{i}\right)=1 / N=1 / 16 \text {. }
$$

In this case, the entropy of the system with a finite number of states is maximum.

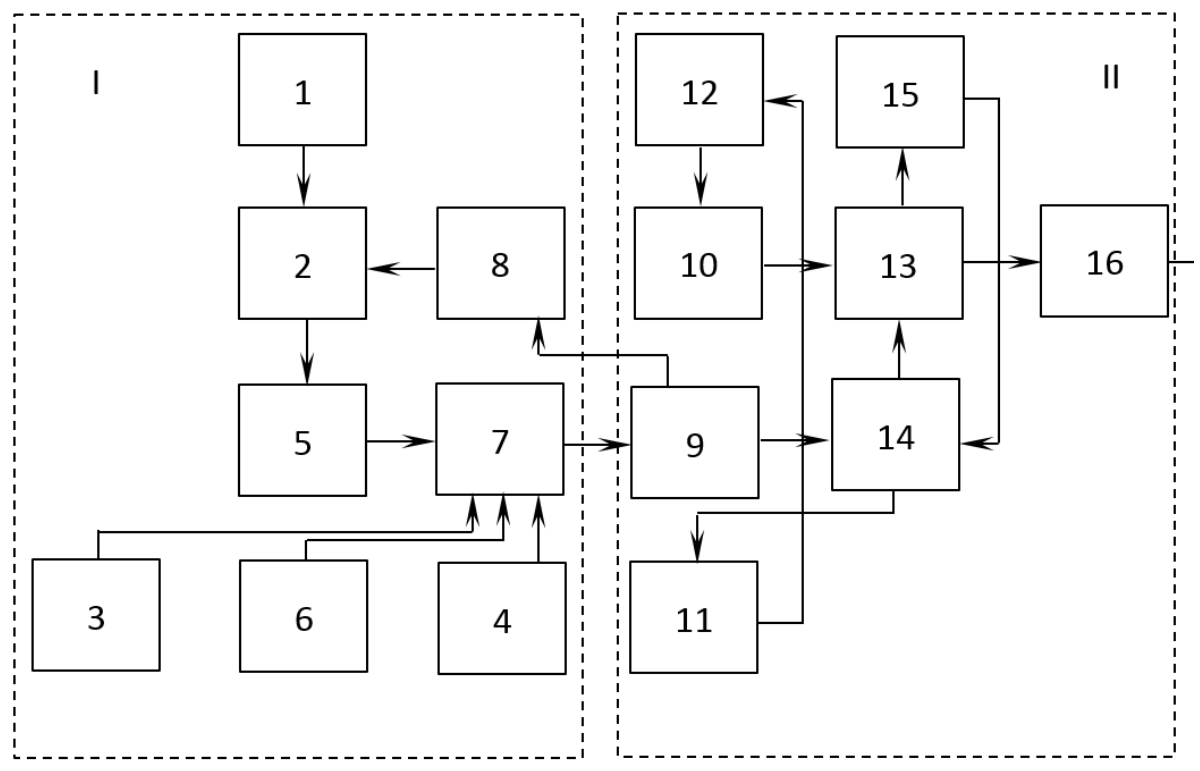

Figure 1. Logical model of a gasoline generator:

I - gasoline engine; II - alternator; 1- tank; 2 - carburetor; 3 - ignition system; 4 - start-up system; 5 - gas distribution system; 6 - engine lubrication system; 7 - connecting rod-piston group with a cranked shaft; 8 - frequency regulator; 9 - iron rotor; 10 - rotor windings; 11 - contact rings; 12 - brush assembly; 13 - main and additional stator windings; 14 - excitation winding; 15 - automatic voltage regulator; 16 - conductors

The initial entropy of the system is determined by the number of possible states:

$$
H\left(S_{i}\right)=\sum_{i=1}^{n} P\left(N_{i}\right) \log _{2} P\left(N_{i}\right)=-16 \frac{1}{16} \log _{2} \frac{1}{16}=4 \text { бim. }
$$

Denote by $m_{1}$ - the number of units in each row of the table, $m_{0}$ - the number of zeros in the same line. The residual uncertainty in the control of each parameter in the first step is calculated by the formula

$$
H\left(\frac{A}{Z_{k}}\right)=\frac{m_{1}}{N} \log _{2} m_{1}+\frac{m_{0}}{N} \log _{2} m_{0} .
$$

\begin{tabular}{|c|c|c|c|c|c|c|c|c|c|c|c|c|c|c|c|c|c|}
\hline \multirow{2}{*}{$\begin{array}{c}\text { Diagnostic } \\
\text { parameter } \\
Z_{k}\end{array}$} & \multicolumn{16}{|c|}{ Get up } & \multirow{2}{*}{$H\left(\frac{A}{Z_{k}}\right)$} \\
\hline & $A_{1}$ & $A_{2}$ & $A_{3}$ & $A_{4}$ & $A_{5}$ & $A_{6}$ & $A_{7}$ & $A_{8}$ & $A_{9}$ & $A_{10}$ & $A_{11}$ & $A_{12}$ & $A_{13}$ & $A_{14}$ & $A_{15}$ & $A_{16}$ & \\
\hline 1 & 0 & 1 & 1 & 1 & 1 & 1 & 1 & 1 & 1 & 1 & 1 & 1 & 1 & 1 & 1 & 1 & 3,662 \\
\hline 2 & 0 & 0 & 1 & 0 & 0 & 0 & 0 & 0 & 0 & 1 & 1 & 1 & 1 & 1 & 1 & 1 & 3 \\
\hline 3 & 1 & 1 & 0 & 1 & 1 & 1 & 1 & 1 & 1 & 1 & 1 & 1 & 1 & 1 & 1 & 1 & 3,662 \\
\hline 4 & 1 & 1 & 1 & 0 & 1 & 1 & 1 & 1 & 1 & 1 & 1 & 1 & 1 & 1 & 1 & 1 & 3,662 \\
\hline 5 & 0 & 0 & 0 & 0 & 0 & 0 & 0 & 0 & 0 & 1 & 1 & 1 & 1 & 1 & 1 & 1 & 3,011 \\
\hline 6 & 1 & 1 & 1 & 1 & 1 & 0 & 1 & 1 & 1 & 1 & 1 & 1 & 1 & 1 & 1 & 1 & 3,662 \\
\hline 7 & 0 & 0 & 0 & 0 & 0 & 0 & 0 & 0 & 0 & 1 & 1 & 1 & 1 & 1 & 1 & 1 & 3,011 \\
\hline 8 & 0 & 0 & 0 & 0 & 0 & 0 & 0 & 0 & 0 & 1 & 1 & 1 & 1 & 1 & 1 & 1 & 3,011 \\
\hline 9 & 0 & 0 & 0 & 0 & 0 & 0 & 0 & 0 & 0 & 1 & 1 & 1 & 1 & 1 & 1 & 1 & 3,011 \\
\hline 10 & 0 & 0 & 0 & 0 & 0 & 0 & 0 & 0 & 0 & 0 & 0 & 0 & 0 & 0 & 0 & 1 & 3,662 \\
\hline 11 & 0 & 0 & 0 & 0 & 0 & 0 & 0 & 0 & 0 & 0 & 0 & 0 & 0 & 0 & 0 & 1 & 3,662 \\
\hline 12 & 0 & 0 & 0 & 0 & 0 & 0 & 0 & 0 & 0 & 0 & 0 & 0 & 0 & 0 & 0 & 1 & 3,662 \\
\hline 13 & 0 & 0 & 0 & 0 & 0 & 0 & 0 & 0 & 0 & 0 & 0 & 0 & 0 & 0 & 0 & 1 & 3,662 \\
\hline 14 & 0 & 0 & 0 & 0 & 0 & 0 & 0 & 0 & 0 & 0 & 0 & 0 & 0 & 0 & 0 & 1 & 3,662 \\
\hline 15 & 0 & 0 & 0 & 0 & 0 & 0 & 0 & 0 & 0 & 0 & 0 & 0 & 0 & 0 & 0 & 1 & 3,662 \\
\hline 16 & 0 & 0 & 0 & 0 & 0 & 0 & 0 & 0 & 0 & 0 & 0 & 0 & 0 & 0 & 0 & 0 & \\
\hline
\end{tabular}

The results of the calculation of the residual entropy are given in the last column of table 1.

Table 1. Table of states of the gasoline generator 
Based on the calculations, the entropy diagram of the system is constructed, which allows to establish the informative significance of the diagnostic parameter.

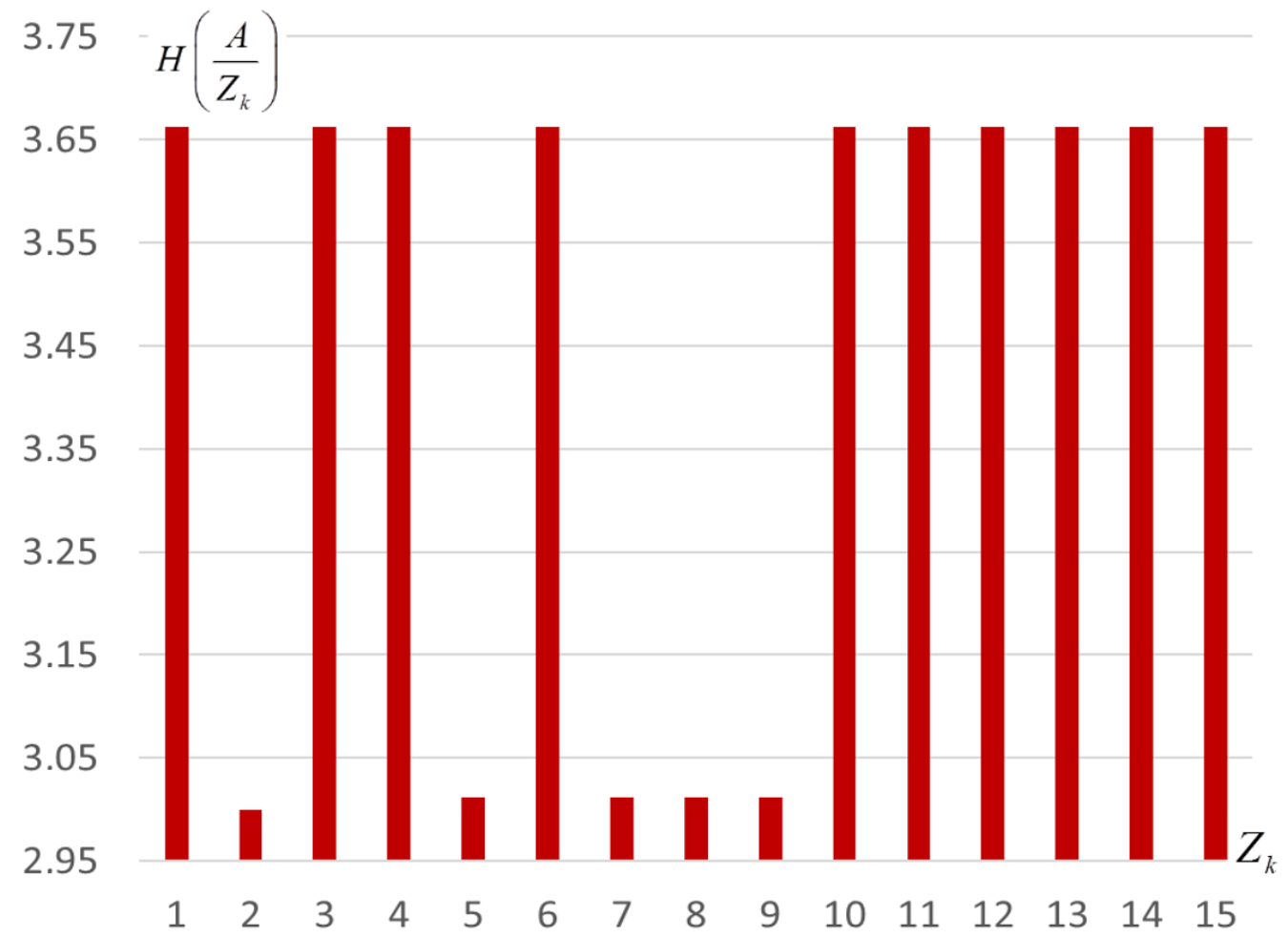

Figure 2. Entropy diagram of a gasoline generator

It is true that the element of the system that has the lowest residual entropy provides the most information about its state, and therefore it must be monitored first. This parameter in the first step will be $Z_{2}$. That is, looking at the block diagram of ADEE based on the internal combustion engine (Fig. 1), this number corresponds to the carburetor. The next elements that significantly affect the entropy of the system will be $Z_{5}, Z_{7}, Z_{8}, Z_{9}$. These numbers correspond to the timing system, cylinder-piston group, speed controller and rotor iron.

For the diagnostic system to work, it is necessary to operate with physical quantities (the value of the diagnostic parameters of the system), so we note the following.

The condition of the carburetor can be determined by the presence of fuel in the cylinder and exhaust in the compressor mode.

The operation of the timing system and the cylinder-piston group can be assessed by the magnitude of the starter current when the engine is running in compressor mode.

The serviceability of the speed controller can be assessed by analyzing the curve of the generated voltage.

The main reason for malfunction of the rotor iron is its demagnetization. The diagnostic parameter of the absence or low value of the magnetic field strength is the low value of the voltage on the stator windings.

We apply a similar approach to determine the parameters of the diesel generator (Fig. 3). The diesel generator system consists of $N=16$ elements. For possible states, we take the failure of each element. We plan to control the status of an autonomous source by the number of parameters equal to the number of elements $k=16$. The states of the system in case of failure of each element are summarized in the table (Table 2). The probability of failure of each element for preliminary consideration is assumed to be equal to:

$P\left(S_{i}\right)=1 / N=1 / 16$

In this case, the entropy of the system with a finite number of states is maximum.

The initial entropy of the system is determined by the number of possible states:

$$
H\left(S_{i}\right)=\sum_{i=1}^{n} P\left(N_{i}\right) \log _{2} P\left(N_{i}\right)=-16 \frac{1}{16} \log _{2} \frac{1}{16}=4 \text { бim. }
$$

Denote by $m_{1}$ - the number of units in each row of the table, $m_{0}$ - the number of zeros in the same line. The residual uncertainty in the control of each parameter in the first step is calculated by formula (3). The results of the calculation of the residual entropy are given in the last column of table 2 . 


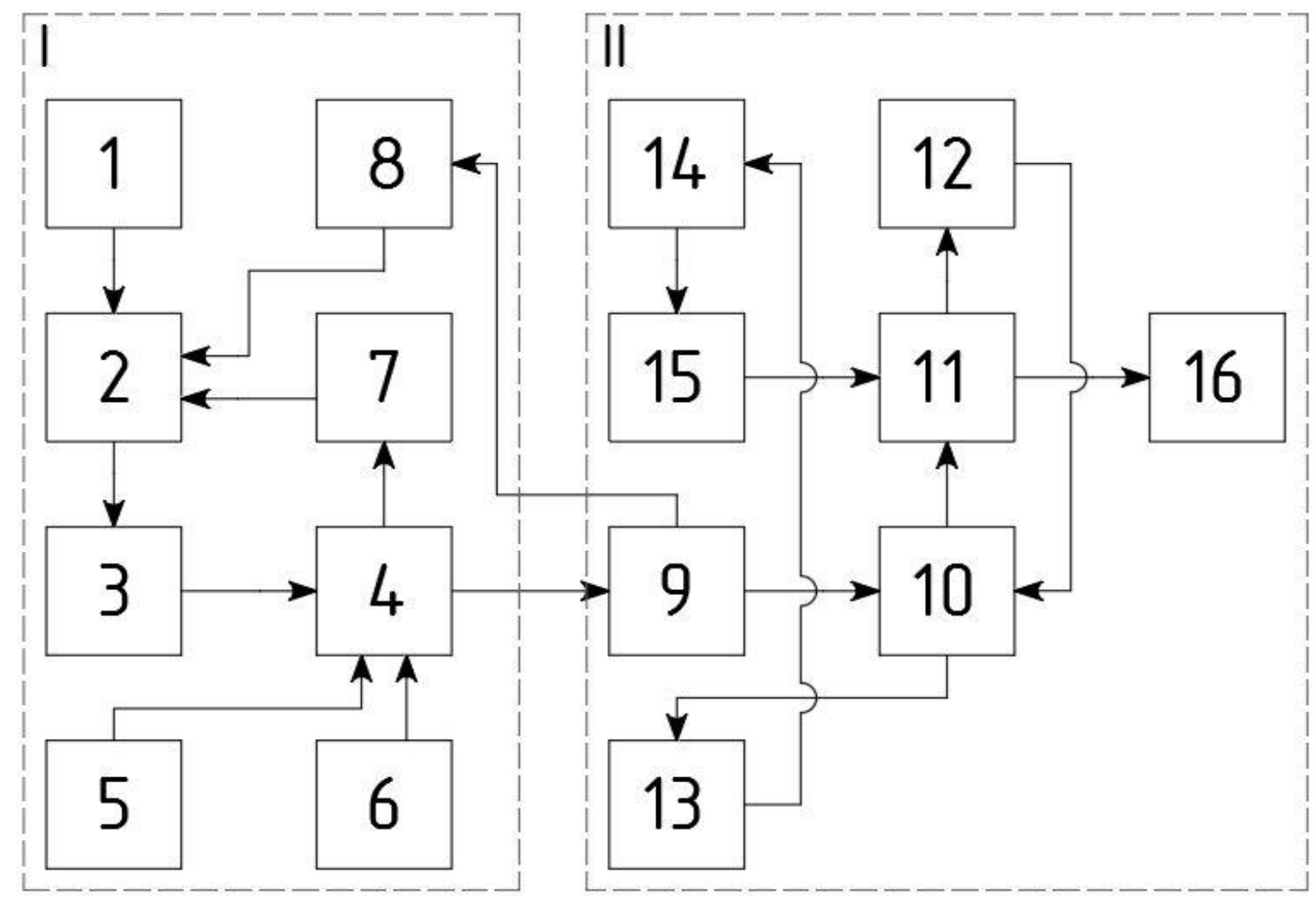

Figure 3. Logic model of a diesel generator:

I - Diesel engine; II - Synchronous generator; 1-tank; 2 - high pressure pump; 3 - nozzle; 4 - connecting rod-piston group with a cranked shaft; 5 - starter; 6 - engine lubrication system; 7 - gas distribution system; 8 - frequency regulator; 9 - iron rotor; 10 - rotor windings; 11 - contact rings; 12 - brush assembly; 13 - main and additional stator windings; 14 - excitation winding; 15 - automatic voltage regulator; 16 - conductors

Table 2 - Table of states of the diesel generator

\begin{tabular}{|c|c|c|c|c|c|c|c|c|c|c|c|c|c|c|c|c|c|}
\hline $\begin{array}{c}\text { Diagnostic } \\
\text { parameter } \\
Z_{k}\end{array}$ & $A_{1}$ & $A_{2}$ & $A_{3}$ & $A_{4}$ & $A_{5}$ & $A_{6}$ & $A_{7}$ & $A_{8}$ & $A_{9}$ & $A_{10}$ & $A_{11}$ & $A_{12}$ & $A_{13}$ & $A_{14}$ & $A_{15}$ & $A_{16}$ & $H\left(\frac{A}{Z_{k}}\right)$ \\
\hline 1 & 0 & 1 & 1 & 1 & 1 & 1 & 1 & 1 & 1 & 1 & 1 & 1 & 1 & 1 & 1 & 1 & 3,663 \\
\hline 2 & 0 & 0 & 0 & 0 & 0 & 0 & 0 & 0 & 0 & 1 & 1 & 1 & 1 & 1 & 1 & 1 & 3,011 \\
\hline 3 & 0 & 0 & 0 & 0 & 0 & 0 & 0 & 0 & 0 & 1 & 1 & 1 & 1 & 1 & 1 & 1 & 3,011 \\
\hline 4 & 0 & 0 & 0 & 0 & 0 & 0 & 0 & 0 & 0 & 1 & 1 & 1 & 1 & 1 & 1 & 1 & 3,011 \\
\hline 5 & 1 & 1 & 1 & 1 & 0 & 1 & 1 & 1 & 1 & 1 & 1 & 1 & 1 & 1 & 1 & 1 & 3,663 \\
\hline 6 & 1 & 1 & 1 & 1 & 1 & 0 & 1 & 1 & 1 & 1 & 1 & 1 & 1 & 1 & 1 & 1 & 3,663 \\
\hline 7 & 0 & 0 & 0 & 0 & 0 & 0 & 0 & 0 & 0 & 1 & 1 & 1 & 1 & 1 & 1 & 1 & 3,011 \\
\hline 8 & 0 & 0 & 0 & 0 & 0 & 0 & 0 & 0 & 0 & 1 & 1 & 1 & 1 & 1 & 1 & 1 & 3,011 \\
\hline 9 & 0 & 0 & 0 & 0 & 0 & 0 & 0 & 0 & 0 & 1 & 1 & 1 & 1 & 1 & 1 & 1 & 3,011 \\
\hline 10 & 0 & 0 & 0 & 0 & 0 & 0 & 0 & 0 & 0 & 0 & 1 & 1 & 1 & 1 & 1 & 1 & 3,046 \\
\hline 11 & 0 & 0 & 0 & 0 & 0 & 0 & 0 & 0 & 0 & 0 & 0 & 0 & 0 & 0 & 0 & 1 & 3,663 \\
\hline 12 & 0 & 0 & 0 & 0 & 0 & 0 & 0 & 0 & 0 & 0 & 0 & 0 & 0 & 0 & 0 & 1 & 3,663 \\
\hline 13 & 0 & 0 & 0 & 0 & 0 & 0 & 0 & 0 & 0 & 0 & 0 & 0 & 0 & 0 & 0 & 1 & 3,663 \\
\hline 14 & 0 & 0 & 0 & 0 & 0 & 0 & 0 & 0 & 0 & 0 & 0 & 0 & 0 & 0 & 0 & 1 & 3,663 \\
\hline 15 & 0 & 0 & 0 & 0 & 0 & 0 & 0 & 0 & 0 & 0 & 0 & 0 & 0 & 0 & 0 & 1 & 3,663 \\
\hline 16 & 0 & 0 & 0 & 0 & 0 & 0 & 0 & 0 & 0 & 0 & 0 & 0 & 0 & 0 & 0 & 0 & 3,663 \\
\hline
\end{tabular}




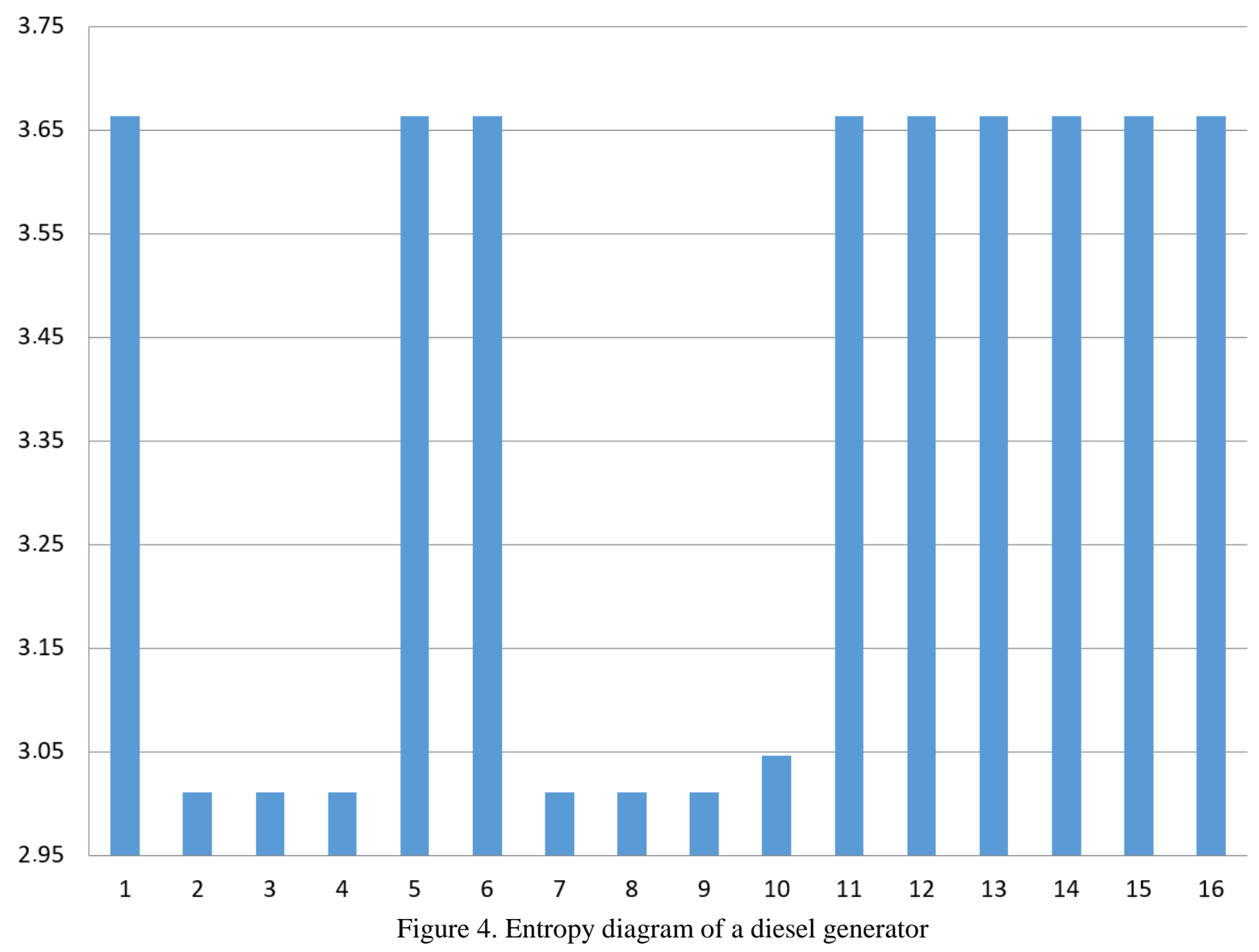

It is true that the element of the system that has the lowest residual entropy provides the most information about its state, and therefore it must be monitored first. This parameter in the first step will be $Z_{10}$. That is, looking at the block diagram of the diesel generator (Fig. 3), this number corresponds to the rotor windings. The next elements that significantly affect the entropy of the system will be $Z_{2}, Z_{3}, Z_{4}, Z_{7}, Z_{8}, Z_{9}$. These numbers correspond to the high pressure pump, the injector, the connecting rod-piston group with a crankshaft, the gas distribution system, the frequency regulator and the iron of the rotor.

For the diagnostic system to work, it is necessary to operate with physical quantities (the value of the diagnostic parameters of the system), so we note the following.

The condition of the high pressure fuel pump can be assessed by the value of the fuel pressure in the main.

The condition of the injectors can be assessed by the value of the correction factors of the fuel supply to the injectors.

The operation of the timing system and the cylinder-piston group can be assessed by the magnitude of the starter current when the engine is running in compressor mode.

The serviceability of the speed controller can be assessed by analyzing the generated voltage curve.

The main reason for malfunction of the rotor iron is its demagnetization. The diagnostic parameter of the absence or low value of the magnetic field strength is the low value of the voltage on the stator windings.

The condition of the rotor windings can be assessed by the resistance of each section.

\section{Conclusions}

1. In this work the structural schemes of typical constructions of ADEE on the basis of the internal combustion engine (petrol and diesel generator) are developed.

2. The table of possible states of system at defect of one node is created. Assuming an equally probable failure of system elements, those that have the greatest impact on the uncertainty of the system are identified. When creating a system of technical diagnostics, their condition should be determined first. For a gasoline generator it is a carburetor, a gas distribution system, a cylinder-piston group, a speed regulator, a rotor iron. For diesel - rotor windings, high pressure pump, injector, connecting rod-piston group with crankshaft, timing system, frequency regulator and rotor iron. However, for non-surgical diagnosis, it is most likely that the number of such items will be increased. 
3. Diagnostic parameters and methods of their determination for diagnosing the above elements of the system are offered.

4. For systems with feedback, the use of such a method leads to uncertainty among the closed elements because the signal of the faulty element affects the other elements.

\section{References}

[1] Sinchuk I. O., 2013

Unconventional and renewable energy sources, Kremenchuk: - 192 p. - ISBN 978-617-639-043-5

[2] Abrashin V. O., Novichonok S. M., 2010

Possibilities of application of alternative sources of electricity in the armed forces of Ukraine, Weapons systems and military equipment, № 3 (23) - p. 7 - ISSN 1997-9568

[3] Gasparyan T. G., 2017

Combustion engine, Big encyclopedia. Electronic version, https://bigenc.ru/technology_and_technique/text/4341616

[4] Gilmiyarov E. B., Tsvetkov V. V., 2006

Multicriteria approach to the choice of ship power plant (in russian), Bulletin of the Moscow State Technical University, volume 9, №3, - p. 12 - http://vestnik.mstu.edu.ru/v09_3_n23/articles/17_gilmi.pdf

[5] x x x, 2003

Rules of classification and construction of sea vessels, Maritime Register of Shipping, Volume 2 - p. 618 - ISBN 5-89331085-3 - http://old.msun.ru/folders/edu_lit/kaf/sv/data/addition/Registr/Registr.pdf

[6] Maughan C. V., 1988

Root-cause diagnostics of generator service failures, Electrical Insulation, Conference Record of the 1988 IEEE International Symposium (IEEE Int Symp Electr Insul). https://www.researchgate.net/publication/224622606_Rootcause_diagnostics_of_generator_service_failures

[7] Zaichenko S., Shevchuk S., Opryshko V., Pryadko S., Halem A., Adjebi A., 2020

Determination of autonomous electrical energy source technical condition based on an internal combustion engine, IEEE KhPI Week on Advanced Technology (KhPIWeek) (pp. 305-308). IEEE

[8] Denysiuk S., 2021

Assessment of consumers power consumption optimization based on demand side management, EUREKA: Physics and Engineering, (2) - 2021. - P. 19-31

[9] Zaichenko S., 2020

Autonomous electric power source energy efficiency improvement by internal combustion engine gases distribution control, 2020 IEEE 7th International Conference on Energy Smart Systems (ESS). - IEEE, 2020. - P. 262-265.

[10] Chetvergov V. A., Ovcharenko S. M., Bukhteev V. F., 2014

Technical diagnostics of locomotives, Moscow: FSBEI Training and Methodological Center for Education in Railway Transport, 2014. - 371 p. - ISBN 978-5-89035-752-6

This article is an open access article distributed under the Creative Commons BY SA 4.0 license. Authors retain all copyrights and agree to the terms of the above-mentioned CC BY SA 4.0 license. 